\title{
Processo de constituição docente dos professores de Fisioterapia de uma instituição de ensino superior do Rio Grande do Sul
}

\author{
Veronica Jocasta Casarotto ${ }^{1}$ \\ Rodrigo Lippold Radünz ${ }^{2}$ \\ Vanessa Lago Morin ${ }^{3}$ \\ Hedioneia Maria Foletto Pivetta ${ }^{4}$
}

\begin{abstract}
Resumo
Buscou-se investigar o processo de constituição docente de professores do curso superior em fisioterapia de uma instituição do interior do RS. A pesquisa teve um enfoque qualitativo, para tanto utilizou-se como instrumento entrevista semiestruturada e análise dos dados que foi feita mediante Análise de Conteúdo proposta por Bardin. Ao final da análise, identificamos que os entrevistados vêm estabelecendo a carreira docente através da prática diária de sala de aula, da reflexão individual e coletiva acerca da sua atuação como professor. A pesquisa também revelou que as experiências práticas anteriores mesmo não tendo relaçáo com a docência, auxiliaram na constituição docente.
\end{abstract}

Palavras-Chave: Docentes. Fisioterapia. Ensino Supeior.

\begin{abstract}
The aim of this study was to investigate the process of teacher education of high school teachers in physiotherapy of an institution in the RS. The research had a qualitative approach, For this, it was used as a semi-structured interview instrument and analysis of data that was done through content analysis proposed by Bardin. At the end of this we identify that the interviewees have been establishing a career teacher through daily classroom practice of individual and collective reflection on his role as teacher. The survey also revealed that previous practical experiences. Even though they had no relation to teaching, helped in the teacher's constitution
\end{abstract}

Keywords: Teachers. Physiotherapy. Higher education.

\footnotetext{
${ }^{1}$ Doutoranda do Programa de Pós-Graduação em Gerontologia Biomédica - PUCRS, Mestre em Gerontologia Biomédica - PUCRS, Especialista em Educação Física Escolar, Especialista em Educação Física Infantil e Anos Iniciais, Graduada em Educação Física e Fisioterapia. E-mail: veronica_casarotto@hotmail.com

${ }^{2}$ Especialista em Fisioterapia Orto-traumatológica e Desportiva, Graduado em Fisioterapia, com estágio no Setor de fisioterapia desportiva do Hôpital National Saint Maurice na França. Atualmente é professor do Curso de Fisioterapia do Centro Universitário Franciscano. E-mail: rodrigoradunz@gmail.com ${ }^{3}$ Mestre em Ciências da Saúde pelo Programa de Mestrado Profissional em Ciências da Saúde (UFSM/HUSM), Especialista em Gestão e Atenção Hospitalar no Sistema Público de Saúde, Graduada em Fisioterapia. Atualmente é professora do Colégio Gandhi - SEG em Curso Técnico em Massoterapia em Santa Maria, RS. E-mail: nessamorin@yahoo.com.br

${ }^{4}$ Doutora e Mestre em Educação pela UFSM, Especialista em Saúde Coletiva, Graduada em Fisioterapia. Atualmente é professora adjunta no Departamento de Fisioterapia e Reabilitação da UFSM e Coordenadora do curso de Graduação em Fisioterapia. E-mail: hedioneia@yahoo.com.br
} 


\section{Considerações introdutórias}

Os constantes estudos/debates relacionados à formaçáo docente vêm gerando, principalmente na última década, inúmeros trabalhos científicos relacionados à formação e atuação dos professores que lecionam em Instituições de Ensino Superior (IES) (CAMPOS, 2011).

Compreendemos que atuar no Ensino Superior (ES) é tarefa complexa e desafiadora, pois além da docência, a profissão vem acompanhada de um conjunto de outros afazeres que precisam e devem ser assumidos pelo professor. Dessa forma, torna-se necessário destacar, que o professor independente do lugar de atuaçâo (Educaçâo Básica ou Ensino Superior), historicamente, vem agregando outras tarefas para além da prática em sala de aula.

Em se tratando de ES, podemos citar como atribuições dos docentes: as atividades administrativas; representaçôes em colegiados e departamentos; além de outras tantas relacionadas ao ensino, pesquisa e extensão. Além disso, todas as atividades assumidas pelos professores precisam funcionar harmoniosamente para que aconteça o bom funcionamento e a organização das instituiçóes, evitando o acúmulo de atividades e uma sobrecarga de trabalho para os docentes (CUNHA, 2007).

Morosini (2006), em seus estudos, demonstra preocupação em discutir aspectos referentes à formação em todos os níveis de ensino, sob o olhar de que o professor está em constante constituição, marcado pelo envolvimento de estar colocando o conhecimento e o saber fazer a serviço de outro ser humano. Torna-se imprescindível compreender os caminhos percorridos pelos docentes do ES, vivendo numa atual sociedade de informaçóes constantes e de conhecimentos necessários à prática docente, onde a todo o momento acontecem ressignificaçôes no cenário educacional que de certa maneira interferem na constituição docente. Confiamos que para conhecer o universo docente, é necessário refletir sobre o processo de formação dos professores especificamente para atuação no ES. Para tanto, é imprescindível levar em consideração aspectos teórico-práticos adquiridos na graduação e atuação profissional (GHEDIN; ALMEIDA; LEITE, 2008).

Neste sentido, acreditamos na importância em investigar como os profissionais se tornam professores para atuar no ES, tendo como referência a Lei de Diretrizes e Bases da Educação 9.394 de 1996 (BRASIL, 1996), em seu inciso II e III do artigo 52, a qual indica que as IES deverão ter pelo menos, um terço do corpo docente com titulação acadêmica de mestrado ou doutorado. Sendo que, esta mesma fração de docentes precisa trabalhar em regime de tempo integral. Faz-se necessário destacar que essas são exigências atribuídas pelo Governo Federal no que tange a docência para o ES.

Para atuar em IES nos dias atuais é preciso ter titulação mínima exigida nos editais de seleção. Este pode-se afirmar é o principal pré-requisito para atuar no $E S$, entretanto, isto não significa que o professor esteja preparado para atuar no contexto educacional (VASCONCELLOS, 2002).

Diante disso, entendemos que a realização deste estudo poderá revelar os caminhos percorridos pelos docentes durantes os primeiros anos como professores de IES. Confiamos que questóes como as dificuldades, os desafios, as conquistas, entre outras, poderão emergir da pesquisa, indicando como esses acontecimentos estão se refletindo na profissão docente (CASTELLI; PEDRINI, 2012).

Ainda segundo os autores supracitados Castelli e Pedrini (2012), pensar a docência no ES remete à reflexão sobre o processo de formação universitária, considerando seus aspectos teóricos e práticos, buscando 
a compreensão de como nos constituímos docentes e de que compreensão de saberes se faz necessário lançar mão para docência, que atenda aos desafios de uma formação cada vez mais plural, científica, qualificada tanto no aspecto da formação pessoal como a profissional.

Nesse sentido, este estudo tem por objetivo compreender os elementos que influenciaram no processo de constituição da profissão docente dos professores de Fisioterapia de uma Instituição de Ensino Superior do interior do estado do Rio Grande do Sul.

\section{Procedimentos metodológicos}

Trata-se de uma pesquisa de natureza qualitativa que, no entendimento de Cauduro (2004), é aquela que procura explorar a fundo conceitos, atitudes, comportamentos, opinióes e atributos do universo pesquisado, avaliando aspectos emocionais e intencionais, implícitos nas opinióes dos sujeitos, empregando entrevistas individuais, técnicas de discussão em grupo, observaçóes e estudo documental.

De acordo com Gil (2011, p. 28) a pesquisa descritiva, "têm como objetivo primordial a descrição das características de determinada população ou fenômeno ou o estabelecimento de relaçóes entre variáveis".

Como instrumentos foram utilizados entrevistas semiestruturadas mediante perguntas abertas, às quais foram respondidas individualmente pelos professores. Gil (2011, p.109) define a entrevista como:

A técnica em que o investigador se apresenta frente ao investigado e lhe formula perguntas, com o objetivo de obtenção dos dados que interessam a investigação. A entrevista é, portanto, uma forma de interação social. Mais especificamente, é uma forma de diálogo assimétrico, em que uma das partes busca coletar dados e a outra se apresenta como fonte de informação.

Importa destacar que as perguntas utilizadas para realização das entrevistas foram adaptadas de Pivetta (2006) e Maciel (2000). Tais questionamentos foram divididos em três blocos, sendo o primeiro composto por "dados de identificação"; o segundo com questôes sobre o "contexto referente a formação e o cotidiano de trabalho dos docentes" e o terceiro bloco buscou abranger as "concepçôes dos docentes em relação a sua atuação como docente do ES".

O grupo pesquisado foi composto por professores do curso de Fisioterapia de uma IES do interior do estado do Rio Grande do Sul, que se enquadraram nos critérios de inclusáo a seguir: estar atuando como professor do curso de fisioterapia da Instituição; possuir titulação mínima de mestre (mestrado acadêmico) e ter experiência entre 5 a 10 anos como docente na Instituiçấo. Foram excluídos da pesquisa professores que não se encaixaram nos critérios descritos.

A coleta de dados aconteceu nas dependências da Instituição, no período de setembro à outubro de 2014. Importa destacar que esta coleta somente teve início após a autorização e aprovação do Comitê de Ética e Pesquisa da Instituição de origem, a qual está registrada com o parecer nº 775.989.

Registra-se que as entrevistas foram gravadas e, posteriormente transcritas em sua íntegra para interpretação e análise. Os dados foram analisados por meio da análise de conteúdo, conforme os pressupostos orientados/defendidos por Laurence Bardin (2009). 
De acordo com a autora supracitada, a análise da pesquisa é utilizada para ressaltar as palavras, frases e expressōes dentro de um texto ou de vários outros textos. Ainda conforme Bardin (2009), a análise de conteúdo representa um conjunto de técnicas de análise das comunicaçôes visando obter, por procedimentos sistemáticos e objetivos de descrição do conteúdo das mensagens, indicadores que permitam a inferência de conhecimentos relativos às condiçôes de produção e recepção das mensagens. Isso de acordo com a autora possibilita o enriquecimento na leitura dos dados coletados.

Bardin (2009) orienta para que esse momento seja dividido em três fases distintas: a primeira, denominada pré-análise, referindo-se ao exato momento em que o material é organizado; a segunda, a qual denomina de descrição analítica, faz referência ao momento no qual o material coletado é submetido a uma análise sistemática e aprofundada, tendo como base o referencial teórico do estudo. Nesta recomenda utilizar os procedimentos de codificaçãa, classificação e categorização, pois entende que tais procedimentos podem auxiliar o pesquisador; e, por fim, a última etapa consiste na interpretação referencial, ou seja, quando as análises realizadas passam por uma reflexão muito mais intensa, pois segundo a autora este momento deve-se tentar localizar elementos que possam estar ocultos.

\section{Resultados}

Participaram da pesquisa cinco (5) professores $^{5}$, conforme Tabela 1 a seguir:

Tabela 1 - Docentes do curso superior em Fisioterapia que fizeram parte da amostra do estudo.

\begin{tabular}{|c|c|c|}
\hline Professores & $\begin{array}{c}\text { Tempo de formaçáo em curso } \\
\text { Superior (anos) }\end{array}$ & $\begin{array}{c}\text { Experiência profissional } \\
\text { docente (anos) }\end{array}$ \\
\hline Violeta & 18 & 9 \\
\hline Rosa & 13 & 5 \\
\hline Cravo & 16 & 22 \\
\hline Tulipa & 16 & 8 \\
\hline Orquídea & 15 & 6 \\
\hline
\end{tabular}

Fonte: os autores, 2014.

A partir da leitura e análise das respostas submeteram-se os conteúdos, seguida de interpretação referencial proveniente de exaustivas leituras e identificação de elementos ocultos nos discursos. A realização desta etapa permitiu elencar três categorias de análise: A primeira foi nomeada de Ensino Acadêmico Baseado em Experiências de Núcleo Profissional, uma segunda categoria intitulada Inserçâo na Docência e por fim, uma última denominada Formação por Módulos Integrados e Reprodução de Modelo Tradicional.

\section{Ensino Acadêmico Baseado em Experiências de Núcleo Profissional}

Esta categoria permitiu desvelar que os docentes participantes da pesquisa demonstraram a utilização da prática profissional como fisioterapeutas nas atuaçôes como docentes do ES, entre outras competências que os mesmos acreditam exercer.

5 Utilizamos nomes fictícios para a identificação dos professores, permanecendo assim o sigilo de informaçóes asseguradas através do Termo de Consetimento Livre e Esclarecido e o Termo de Confidencialidade. 
Os docentes foram questionados sobre as competências necessárias para atuação no curso de fisioterapia? [...] querer ser docente e também amar esta profissão, e ter a certeza que é isso que você quer sempre correr atrás para oferecer o melhor aos alunos (Rosa).

O professor tem que ter experiência, é imprescindível, não tem como você estar passando prática para um aluno, ainda mais que o fisioterapeuta é $80 \%$ prática. Nenhum livro vai te ensinar como manusear um paciente, o professor precisa de um período de prática (Orquídea).

[...] não ser acomodado, pois com o uso da internet os alunos buscam mais, e os alunos querem mais as coisas do tempo deles (Tulipa).

De acordo com os autores Almeida e Batista (2011), o professor deve ser um profundo conhecedor do assunto que ensina, como se apenas esse aspecto assegurasse sua competência docente; fato que contribui para a falta de qualificação pedagógica. Os mesmos autores salientam ainda a fragilidade pedagógica, as aulas ministradas pelos docentes são baseadas em aprendizagem, ou seja, em suas experiências práticas.

No entanto, a pesquisa revela que há pouco interesse dos docentes pela capacitação didático-pedagógica. Tal afirmação vai ao encontro das pesquisas realizadas por Foresti (2001), que indica haver poucas disciplinas pedagógicas obrigatórias nos cursos de pós-graduação. Dessa forma, como "exigir" dos docentes o interesse por cursos pedagógicos, se em suas formaçōes eles recebem conhecimentos limitados sobre tal área.

É importe que as IES proporcionem momentos de formação docente, com caráter coletivo para que os professores possam trocar suas experiências e assim, refletir coletivamente sobre a prática. Para tanto, é necessário que os docentes busquem participar e debater nesses espaços, contribuindo com a sua formação e com a formação dos seus pares.

A pesquisa também revelou que a instituição a qual os docentes entrevistados lecionam exige que os mesmos participem dos espaços formativos oferecidos. Segundo os entrevistados, tal iniciativa, busca auxiliar e incentivar a prática pedagógica do corpo docente da instituição. De acordo com Tardif (2003, p.17):

[...] embora os professores utilizem diferentes saberes, essa utilização se dá em função do seu trabalho e das situações, condicionamentos e recursos ligados a esse trabalho. [...] as relações dos professores com os saberes nunca são relaçóes estritamente cognitivas: são relaçóes mediadas pelo trabalho que lhes fornece princípios para enfrentar e solucionar situaçóes cotidianas.

A presente pesquisa possibilitou a descoberta de que os docentes investiram ao longo de sua carreira em cursos de formação específicos de núcleo profissional - fisioterapia; e, mais ainda, salientam a importância destes conforme observado na fala a seguir:

Raramente eu faço curso na área da educação, nas práticas reflexivas, aprendo bastante na visão da docência, os cursos da minha área eu priorizo eles (Orquídea). 
O depoimento anterior faz emergir certa preocupação com relação à procura e/ou investimento na área educacional, pois entendemos ser imprescindível o professor investir na profissão. Tal afirmação não significa desmerecer ou desvalorizar os cursos realizados na área da fisioterapia, mas confiamos ser importante que o professor esteja em constante aprendizado, pois assim, conseguirá desempenhar melhor suas atribuições.

Acredita-se que o professor (independente do local de atuação) precisa estar num processo de constante (re) construção, pois ao passar dos anos o conhecimento já adquirido será aperfeiçoado e resignificado a partir de diferentes ações que promovem a reflexão, o debate, ou seja, momentos que contribuem para o professor cada vez mais melhorar sua prática pedagógica.

Cabe ressaltar que embora, os professores possuam experiências significativas e trajetórias de estudos em determinada área de conhecimento, é comum nas diferentes IES, o predomínio do "despreparo e até um desconhecimento científico do que seja o processo de ensino e aprendizagem, pelo qual passam a ser responsáveis a partir do instante em que ingressam na sala de aula" (PIMENTA; ANASTASIOU 2002, p. 37).

Nóvoa (1997, p. 27), indica que os professores vivenciam algumas situaçôes consideradas conflitantes e por essa razão, são obrigados a enfrentar e superar tais adversidades. Nas palavras do autor, "[...] o profissional competente possui capacidades de autodesenvolvimento reflexivo [...]. A lógica da racionalidade técnica opóem-se sempre ao desenvolvimento de uma práxis reflexiva". Ainda segundo o autor, o aprender contínuo é essencial e, se concentra em dois pilares: o próprio indivíduo, como agente e a instituição (universidade), como ambiente de crescimento profissional.

Para desempenhar a profissão docente é necessário tecer algumas consideraçôes sobre o professor reflexivo como sujeito que diariamente precisa disponibilizar um tempo/período para si mesmo. Um momento para que este possa se fazer docente também a partir da reflexão da sua prática pedagógica.

Compreendemos que este momento de reflexão é crucial e indispensável a todo docente, porém, é fato que não é fácil dispor de momentos para autorreflexão, pois diferentes fatores interferem na vida diária, independentes da funçâo que se desempenha no mundo do trabalho. Cada vez menos disponibilizamos tempo para refletir sobre nós mesmos, sobre a prática diária, sobre o lazer, etc., devido muito provavelmente à evolução tecnológica que vivemos diariamente, mas não somente isto há tantas outras funções/obrigações que impedem ou limitam de poder desfrutar de um tempo.

Para Zeichner (1995) o professor reflexivo consegue reconhecer a riqueza da própria experiência. De acordo com o autor, o ato de refletir a partir da própria prática permite ao professor formular outras teorias e assim sucessivamente reelaborar seu conhecimento.

Nesse sentido, o ato de reflexão não deve jamais ser um ato isolado. E, sim algo que seja compartilhado com os demais companheiros de profissão. Para assim, promover e incentivar debates, discussões que possam gerar um novo conhecimento em torno da prática docente. Logo, o docente que não reflete sua prática, que não interage com seus pares e até mesmo com os alunos, pois não evolui e, de certa maneira fica "trancafiado" em sala de aula.

Vasconcellos (1995) aponta que o espaço de reflexão crítica, coletiva e constante sobre a prática é essencial para que o trabalho seja transformador. Para tanto, é necessário compromisso e responsabilidade para que se possa avançar na tentativa de melhorar e qualificar a atuaçáo pedagógica do professor e consequentemente a educação. 
A aprendizagem e o fazer reflexivo são essenciais no processo de construção do conhecimento, onde o ensinar precisa ser feito de forma dialógica com as exigências empreendidas, bem como os contextos socioeconômicos, políticos e culturais.

Cunha (2007, p. 16), evidencia que "a relação da teoria com a prática é sempre mediada pela cultura, e essa condição precisa ser percebida pelo professor". Alarcão em seus estudos sobre a formação concorda com o pensamento de Schön, que define essa atividade como "[...] atuação inteligente e flexível, situada e reativada" (ALARCÁO, 1996, p. 13), sendo o resultado de uma mistura entre "ciência, técnica e arte".

O autor supracitado ainda pontua que atuação profissional é definida como um saber-fazer sólido, teórico e prático, inteligente e criativo, numa dinâmica que o possibilita agir em contextos instáveis como a sala de aula. Para tanto, a universidade necessita de uma estrutura curricular voltada para a prática, mas, sobretudo com forte teor reflexivo, além de constante incentivo aos docentes para que auxiliem os futuros professores a desenvolver competências necessárias para agirem em situaçóes de incerteza e indefinição (ALARCÃO, 1996, p. 26).

Para Cunha (2007, p. 15) a "prática cada vez mais vem sendo valorizada como espaço de construção de saberes, quer na formaçáo de professores, quer na aprendizagem dos alunos”.

Castelli e Pedrini (2012) a formação e a construção de saberes dos profissionais que atuam na docência do ES constituem-se num processo de preparação político/pedagógica que não pode ser desvinculada do desenvolvimento pessoal e institucional.

A prática docente não se concretiza, apenas, na sala de aula da graduação, pois sua epistemologia sofre influências do $e u$ docente e do $e u$ institucional. Assim, o professor vai se apropriando de métodos e instrumentos com os quais praticará sua docência.

Segundo Cunha (2006), a formação docente tem sido entendida, por força da tradição e ratificada pela legislação, como atinente quase que exclusivamente aos saberes do conteúdo de ensino. Espera-se que o professor seja, cada vez mais, um especialista em sua área, tendo-se apropriado, com o concurso da pós-graduação Stricto Sensu, do conhecimento legitimado academicamente no seu campo científico. O domínio do conteúdo, por sua vez, deve ser alicerçado nas atividades de pesquisa que garantam a capacidade potencial de produção científica (CUNHA, 2006).

Entretanto, para Machado, Machado e Viera (2011) o corpo docente é recrutado entre profissionais dos quais se exige mestrado ou doutorado, o que supostamente os torna mais competentes na comunicaçáo do conhecimento.

\section{Inserção na Docência}

Nesta categoria foi possível identificar que cada um dos docentes colaboradores na pesquisa se inseriu na docência de maneira distinta, mas a principal relação entre alguns deles (Violeta, Orquídea e Tulipa) é a inexperiência com a atividade docente antes de lecionar na instituição a qual fazem parte.

Meus pais são professores [...] na especialização tive uma disciplina que tinha que dar aula e daí já gostei [...] (Violeta). 
Já trabalhava em UTIs [...] e minha primeira experiência na docência foi aqui [...] o que me ajudou foi a experiência de trabalhar [...] (Orquídea).

[...] analisava os professores, sempre gostei da área de atuação, se era parecido com eles, e aos poucos fui estudando e comecei nesta instituição a docência [...] (Tulipa).

Entre os cinco professores entrevistados, dois deles possuíam experiência docente antes de assumir a função na presente Instituição;

[...] comecei na universidade pública como substituta, e três meses depois entrei aqui nessa instituição (Rosa).

Sai da minha primeira graduação e já entrei na docência superior [...] após a formação da segunda graduação retornei a docência superior (Cravo).

Confiamos que a formação profissional somadas as condiçôes de trabalho influenciam na carreira docente. O saber ensinar incorpora experiências individuais e coletivas, articulando o conhecimento específico do conteúdo (PIMENTA, 2002; TARDIF, 2003).

Segundo Leitinho (2008), a obrigatoriedade que emerge dos compromissos institucionais frente aos desafios que são postos às IES, e que demandam novas formaçóes para os professores, torna imprescindível a aquisiçáo de competências que possibilitem o cumprimento das exigências da sociedade por uma formaçáo profissional sintonizada com as mudanças na educação e no mundo do trabalho.

Ao serem questionados sobre qual seria a sua profissáo todos os entrevistados responderam que são fisioterapeutas e professores universitários.

De acordo com Cruz (2006), no desenvolvimento profissional docente há de se considerar a constituição de uma identidade profissional em que o professor busca a sua biografia, que se constrói com o individual e o coletivo em interação, havendo uma relação com os atributos culturais.

Nesse processo, ocorre um jogo de valores que cria uma identificação pessoal com um grupo ou pessoa, com uma cultura profissional docente que ocorre no processo de interiorizaçáo, de individualização; da constituição das primeiras experiências a partir das influências de pessoas e das relaçóes com outros agentes e com o alunado, supervisores e tutores, gerando um processo permanente de reconstituição; deve-se considerar também o desenvolvimento de uma atitude ante a formação e uma lógica salarial que influi na compreensão sobre o mundo do trabalho do professor.

Quando questionados sobre as competências necessárias para o docente atuar na instituiçáo obteve-se a seguinte resposta, que traduz a visão geral dos entrevistados:

Tem que ser comprometido, conhecimento, disposição, competência, técnica humana tem que buscar o saber diferente, inovação, vestir a camiseta, coleguismo, empatia, dedicação (Violeta). 
No entanto, não são observadas competências profissionais relacionadas à prática educativa, aspectos pedagógicos e perspectivas político-social-comportamentais e coletivas do ser humano. Tais aspectos são observados no trecho a seguir:

[...] dei poucas aulas no mestrado, na nossa área quanto mais prática você for melhor, pois às vezes não precisa ser doutor para ser bom às vezes o especialista ministra uma aula melhor do que o doutor. Então, o mestrado e doutorado te preparam para pesquisa e não para dar aula (Rosa).

De acordo com os relatos dos professores, percebe-se que há ausências de algumas competências para inserção como docente no ES, abaixo alguns autores conceituam essas competências para ministrar as aulas no ES.

Perrenoud (2000) propóe dez competências que possibilitam exercer a prática docente: organizar e dirigir situaçôes pedagógicas; administrar a progressão das aprendizagens; conceber e fazer evoluir os dispositivos de diferenciação; envolver os alunos em suas aprendizagens e em seu trabalho; trabalhar em equipe; participar da administração organizacional; informar e envolver; utilizar novas tecnologias; enfrentar os dilemas éticos da profissão e administrar sua formação continuada.

Entretanto, Masetto (2002), de maneira mais sucinta apresenta somente três competências que segundo ele são especificas para o docente de ES: competências em uma determinada área do conhecimento; competência na área pedagógica; competência para o exercício da dimensão política.

Já no entendimento de Vasconcelos (2002), o professor universitário para ser um profissional cada vez melhor, precisa possuir determinadas competências como: formação técnico-científica, para ter domínio técnico do conteúdo a ser ministrado; formação prática, conhecimento da prática profissional para a qual os seus alunos estão se formando; formação política, isto é, reconhecer a educação como uma prática isenta de neutralidade, cujas ações são políticas e intencionais; formação pedagógica, edificada no fazer cotidiano da profissão docente, metodologicamente desenhada, ou seja, para ensinar, em qualquer nível, o professor necessita ter conhecimento didático.

\section{Formação por Módulos Integrados e Reprodução de Modelo Tradicional}

No curso de fisioterapia onde os docentes entrevistados lecionam, houve uma preocupação em atender as necessidades de formação dos alunos. Então, foi proposto o ensino do currículo por meio de módulos integrados. De acordo com Pivetta (2006, p. 48):

[...] uma necessidade do mercado de trabalho na ânsia do alcance da integralidade do cuidado através da conexão entre os diferentes saberes [...] os módulos de ensino que agregam vários conteúdos e professores que devem se relacionar entre si, adotando, em determinados momentos, questóes problematizadoras, como metodologia de ensino-aprendizagem para que o discente obtenha uma formação sólida, estabelecendo relaçôes entre o humano e o técnico-científico [...]. 
Para Zabalza (2004), a estrutura curricular por módulos oferece ao professor o planejamento diferenciado de suas atividades docentes. A metodologia de ensino usada articula de forma dinâmica prática e teorica, ensino e comunidade, por meio da integração dos conteúdos, tendo como pano de fundo as características socioculturais do meio em que esse processo se desenvolve.

Mesmo que os docentes trabalhem em uma perspectiva de disciplinas modulares, não tem como negar a sua formação inicial com metodologias ditas tradicionais. Segundo Schon (2000), no ensino normativo, a prática vem posteriormente à teoria, com o objetivo de aplicar teorias e técnicas ensinadas durante o curso. Tais aspectos são observados no relato a seguir:

Eu trago muitas coisas da minha formação, porque eu acho que as especificidades das disciplinas da minha formação, ensino mais fragmentado eu acho difícil fazer a ligação com outras áreas. Mesmo sendo currículos diferentes no que eu fui formada e no que sou docente (módulos), ensino muita coisa da minha formação (Orquídea).

A docência tem sido considerada uma "semiprofissão", onde o domínio de conteúdos específicos de disciplinas, na maioria das vezes, é suficiente para assumir a capacidade de ensiná-los. A autora acrescenta que, atualmente, essas características históricas são consideradas insuficientes, embora não se discuta que sejam necessárias (COSTA, 2007).

Segundo Almeida e Batista (2011) as mudanças nas funções do docente implicam modificações em sua maneira de conceber e desenvolver as práticas pedagógicas. Para muitos, é difícil desenvolver as tarefas propostas nos métodos ativos, visto que os conteúdos e atividades são integrados em temas e/ou em necessidades de saúde e não mais em disciplinas, como no currículo tradicional. A perda de domínio do conteúdo único e específico de sua especialidade, a necessidade de integrar conhecimentos, a participação em atividades interdisciplinares de planejamento e avaliação, aliadas à mudança de papel de "transmissor de conteúdo" para ativador da aprendizagem, tornam o processo de mudança de difícil aceitação.

Confiamos na necessidade do professor de fisioterapia ter uma prática educativa adequada para além do conhecimento especializado, tornando esse conhecimento pertinente e funcional, pois geralmente a graduação no curso de fisioterapia se restringe mais aos conhecimentos técnicos específicos da área (PIVETTA, 2006).

\section{Considerações finais}

Ao tecer considerações a cerca dos resultados analisados, observou-se que a formação inicial e a pós-graduação dos entrevistados ofereceu subsídios insuficiente para a atuação como docente no ES.

Com relação à atuação docente, os professores trazem diversas referências da sua ação prática para o ensino acadêmico. Constatou-se que os docentes acreditam na importância de investir em cursos específicos de suas áreas de atuação e não para sua formação pedagógica.

Portanto, os professores vêm construindo sua constituição docente através da sua prática diária de sala de aula, em cursos de especialização e de formação didática pedagógica oferecida pela instituiçâa, das trocas 
de experiências com colegas de trabalho e, da reflexão individual. Também é importante, compreender que qualquer experiência anterior mesmo não sendo com a docência, auxiliou no desenvolvimento das aulas, pois os conhecimentos são sempre partilhados, assim como os saberes pessoais, profissionais que estão incluídos desde a formação inicial.

Acredita-se que a busca pelo conhecimento, através de livros, artigos, a experiência na própria profissão, a troca de conhecimento entre colegas auxiliem na constituição docente. Porém, ressalta-se a importância da constituição do saber pedagógico com respaldo teórico e formativo e não somente empírico.

\section{Referências}

ALARCÃO, I. Reflexão crítica sobre o pensamento de D. Schön e os programas de formação de professores. In: ALARCÃO, I. et al. Formaçáa Reflexiva de Professores - Estratégias de Supervisáo. Porto: Porto Editora, 1996. p. 9-40.

ALMEIDA, M. T. C; BATISTA, N.A. Ser docente em métodos ativos de ensino-aprendizagem na formação do médico. Revista Brasileira de Educaçáo Médica, v. 35, n. 4, p. 468-476, 2011.

BARDIN, Laurence. Análise de Conteúdo. 4. ed. Lisboa, Portugal: Ediçóes 70, 2009. 281p.

BRASIL. Lei de Diretrizes e Bases da Educação Nacional. Brasília - DF, Ministério da Educação, 1996.

CASTELLI, M. D. B.; PEDRINI M. A formação docente no contexto do ensino superior. In: ANPED SUL SEMINÁRIO DE PESQUISA EM EDUCAÇÃO DA REGIÃO SUL, 9. 2012. Anais... 2012.

CAMPOS, V. T. B. Docência no ensino superior brasileiro: representaçôes de pós-graduandos de instituiçôes federais de ensino superior. In: REUNIÃO ANUAL DA ANPEd, 34., 2011, Natal. Anais... Natal, 2011.

CAUDURO, M. T. Investigaçáo em Educação Física e esportes: um novo olhar pela pesquisa qualitativa. Novo Hamburgo: FEEVALE, 2004.

COSTA, N. M. S. C. Docência no Ensino Médico: por que é tăo difícil mudar? Rev. Bras. Educ. Med. n. 31, p.21-30, 2007.

CRUZ, M. F. Desarrollo profesional docente. Granada -Docência no Ensino Médico: por que é tão difícil mudar? Rev. Bras. Educ. Med., España, Grupo Editorial Costa NMSC, n. 31, p. 21-30, Universitário, 2006.

CUNHA, M. I. Docência na universidade, cultura e avaliação institucional: saberes silenciados em questão. Revista Brasileira de Educaçáo, Rio de Janeiro - Brasil, v. 11, n. 32, p. 258, 2006.

CUNHA, M. I. O lugar da formação do professor universitário: a condiçáo profissional em questáo. In: CUNHA, Maria Isabel da (Org.). Reflexóes e Práticas em Pedagogia Universitária. Campinas, SP: Papirus, 2007. (Coleção Magistério: formação e trabalho pedagógico). 
FORESTI M.C.P.P. Ação Docente e Desenvolvimento Curricular: Aproximação ao Tema. Ver. ABENO, v. 1, n. 1, p. 13-6, 2001.

GHEDIN, E.; ALMEIDA, M. I.; LEITE, Y. U.F. Formaçáo e professores: caminhos e descaminhos da prática. Brasília: Líber Livro Editora, 2008.

GIL, A. C. Métodos e técnicas de pesquisa social. $6^{\circ}$ ed. São Paulo: Atlas, 2011.

LEITINHO, M. C. A formaçáo pedagógica do professor universitário: dilemas e contradiçōes. Linhas críticas, Brasília, v. 14, n. 26, p. 79-92, jan./jun. 2008.

MACHADO, J. L. M; MACHADO, V. M.; VIEIRA, J. E. Formação e Seleção de Docentes para Currículos Inovadores na Graduação em Saúde. Revista Brasileira de Educaçáo Médica, v. 35, n. 3, p. 326-333, 2011.

MACIEL, A.M.R. Formaçáo na Docência Universitária? Realidade e possibilidades a partir do Contexto da Universidade de Cruz Alta. Santa MarialUFSM 2000. Tese (Doutorado em Educação). Universidade Federal de Santa Maria, 2000.

MASETTO, M. (org.). Docência na universidade. 4. ed. Campinas: Papirus, 2002.

MOROSINI, M. C. Internacionalização na Educação Superior: um modelo em construção. In: Audy J. L. N. e Morosini, M. C (orgs.) Inovaçáo e Empreendedorismo na Universidade. Porto Alegre: EDIPUCRS, 2006.

NÓVOA, Antonio. Os professores e sua formaçáo. Lisboa-Portugal, Dom Quixote, 1997.

PERRENOUD, P. Dez novas competências para ensinar. Porto Alegre. Artmed, 2000.

PIMENTA, Selma Garrido. (org.). Saberes pedagógicos e atividade docente. 3. ed. São Paulo: Cortez, 2002.

PIMENTA, S. G. ANASTASIOU, L. G. C. Docência no Ensino Superior. São Paulo: Cortez, 2002.

PIVETTA, H. M. F. Concepçóes de formaçáo e docência dos professores do Curso de Fisioterapia do Centro Universitário Franciscano. Dissertação (Mestrado em Educação). Universidade Federal de Santa Maria, Santa Maria/RS, Brasil, 2006.

SCHON. D.A. Educando o profissional reflexivo: um novo design para o ensino e a aprendizagem. Porto Alegre: Artmed, 2000.

TARDIF, M. Saberes docentes e formaçáo profissional. 3. ed. Petrópolis/RJ: Vozes, 2003.

VASCONCELLOS, C. S. Para onde vai o professor? Resgate do professor como sujeito de transformação. São Paulo, Libertad, 1995 (coleção subsídios pedagógicos do libertad, vol. I).

VASCONCELLOS, C. S. Coordenaçáo do Trabalho pedagógico: do projeto político-pedagógico ao cotidiano da sala de aula. Sáo Paulo: Libertad, 2002. 
ZABALZA, M. A. O Ensino Universitário: seu cenário e seus protagonistas. Porto Alegre: Artmed. 2004.

ZEICHNER, K. Novos caminhos para o pratica: uma perspectiva para os anos 90. Os professores e sua formação. 2. ed. Portugal: Dom Quixote, 1995. 